\title{
CRÓNICA SOBRE LA REFORMA INSTITUCIONAL ITALIANA
}

\author{
GIANCARLO ROLLA \\ Universidad de Siena
}

Debiendo seleccionar, entre los múltiples eventos de naturaleza constitucional que han marcado la vida política e institucional italiana durante el año, aquéllos que parecen revestir un mayor interés para el estudioso y el observador extranjero, entiendo útil llamar la atención sobre todo respecto de tres sucesos: el intenso, pero infructuoso debate sobre la reforma de la Constitución italiana que ha llevado al Parlamento y a los estudiosos todo el año; los sustanciales cambios que están afectando a nuestro sistema administrativo, sobre todo por lo que concierne a los nuevos criterios de repartición de las competencias administrativas entre el Estado, las Regiones y los entes locales; y, en fin, las recientes iniciativas cara a reforzar el carácter mayoritario del sistema electoral y la naturaleza tendencialmente bipolar del sistema político.

\section{EL ATORMENTADO CAMINO DE LA REFORMA CONSTITUCIONAI}

En cuanto a lo primero, es necesario antes de nada subrayar cómo en el curso del último año gran parte del debate político ha estado monopolizado -además de por las medidas de naturaleza financiera que resultaban necesarias para permitir la convergencia de los indicadores económicos y de las finanzas públicas italianas a los parámetros fijados por el Tratado europeo de Maastricht- primero, por las propuestas de reforma total de la segunda parte de la Constitución italiana elaboradas por la Comisión parlamentaria para las cuestiones regionales; después, por las divisones habidas en el interior de las diversas formaciones políticas -lo mismo de la mayoría que de la oposición-, en orden a la nueva definición de 
algunos institutos y órganos, y por las polémicas que algunas de las soluciones de revisión constitucional apuntadas han alimentado, generando una aguda contraposición entre la Comisión parlamentaria e influyentes grupos y asociaciones representativas de la sociedad y de las instituciones. A tal propósito, son reseñables las posiciones -ásperamente contrarias-, expresadas en bastantes ocasiones, de las asociaciones representativas de la magistratura hostiles a la modificación de algunos artículos de la Constitución en materia de ordenamiento judicial.

La doctrina constitucional italiana no ha permanecido fuera del debate, interviniendo -con posiciones en general críticas- sobre los contenidos de las propuestas parlamentarias de reforma de la Constitución: han sido numerosas tanto las publicaciones producidas por estudiosos o por grupos de investigación, como los congresos, los grupos de estudio y seminarios, entre los cuales merecen significarse los organizados por la Asociación italiana de Derecho Constitucional.

Reflexionando sobre esta experiencia, no puede dejar de constituir objeto de preocupante atención, una vez más, que los propósitos de revisión constitucional hayan permanecido tales, o sea, que las propuestas de reforma no hayan llegado a completar su propio iter. Tal constatación evidencia la dificultad que diversos ordenamientos contemporáneos (no sólo el italiano) encuentran para cuajar un consenso suficiente sobre alteración constitucional, de modo que no parece arriesgado afirmar que se está viviendo una fase de "bloqueo" constitucional. Y la preocupación se acentúa dado que, por un lado, ninguno niega no sólo la oportunidad, sino incluso la necesidad de introducir correctivos sustanciales al texto aprobado en 1947; por otro, se han introducido procedimientos derogatorios de revisión constitucional, con la intención de hacer más ágil la alteración del texto constitucional, y las fuerzas políticas presentes en el Parlamento se han empleado en el debate y en la labor de elaboración de la nueva ley constitucional mediante sus leaders más autorizados.

Tal conjunto de vicisitudes testimonia una sustancial incapacidad de autorreforma del sistema político, juicio que se refuerza si se recuerdan que no han tenido mejor éxito múltiples tentativas de reforma habidas recientemente.

$Y$ sin embargo, por tercera vez, el proceso de reforma constitucional no ha llegado a resultados concretos, de modo que -parafraseando el título de una comedia de un conocido dramaturgo alemán- se prodría hablar al respecto de "resistible ascensión de la Comisión bicameral para las reformas constitucionales".

Ya en el curso de la IX legislatura se instituyó en 1983 una Comisión parlamentaria para las reformas institucionales, la "Comisión Bozzi", que presentó en 1985 algunas propuestas sin que llegaran a surtir ningún efecto concreto. También la XI legislatura pareció abrirse bajo los signos de la reforma constitucional. En 1991 el Presidente de la República, Cossiga, envió un mensaje a las Cámaras invitando al Parlamento a impulsar las reformas, indicando, además, las vías procedimentales para efectuarlas. En 1992, el nuevo Presidente de la República, Scalfaro, subrayaba en un mensaje la exigencia de instituir una nueva Comisión para las reformas que ve la luz el 23 de julio de 1992 (Comisión Iotti-De Mita) y que comienza sus trabajos en septiembre del mismo año. Su actividad consistía, en un primer momento, en la aprobación de una serie de principios directivos para la 
reforma de la segunda parte de la Constitución, puesto que estaba expresamente previsto el ámbito en el que la Comisión podía intervenir. Con este objeto, los labores de la Comisión prosiguieron a lo largo de 1993 mientras, simultáneamente, las Cámaras aprobaban la ley constitucional n. 1 de 1993 que, derogando el art. 138 de la Constitución, prevé un procedimiento singular para la aprobación de la reforma que la misma Comisión bicameral había propuesto. La disolución anticipada de las Cámaras el 16 de junio de 1994 puso fin a este ulterior intento de reforma.

El debate sobre la revisión de la Constitución adquiere impulso en la presente legislatura, y se ha desarrollado esencialmente a lo largo de las siguientes etapas: la aprobación de la ley constitucional n. 1 de 1997, que ha introducido un procedimiento derogatorio respecto del ordinario previsto por el art. 138 cost.; la presentación por parte de la Comisión parlamentaria para las reformas constitucionales de un proyecto de ley constitucional conteniendo una propuesta orgánica de variación de la organización constitucional; el impulso del debate parlamentario sobre tal propuesta en los inicios del año en curso; en fin, la interrupción (y probable abandono) del mismo tras manifestarse una orientación contraria sobre los puntos relevantes de la propuesta de reforma de la Comisión bicameral, en particular los relativos a la elección del Presidente de la República, a la definición de sus tareas y a la transformación de la forma de gobierno de parlamentaria en semipresidencial.

En los pasados meses la Comisión bicameral ha trabajado intensamente, en observancia de los tiempos señalados por la ley constitucional n. 1 de 1997, que fijaba tanto la fecha de inicio de los trabajos de la comisión como la de transmisión al plenum de las asambleas parlamentarias de las propuestas de revisión: en concreto, la comisión parlamentaria para las reformas constitucionales debía transmitir a las Cámaras en seis meses un proyecto preliminar de reforma, mientras que en los sucesivos treintas días cada diputado y senador podía presentar enmiendas sobre cuya base la comisión procedería a la elaboración de la propuesta definitiva.

El iter derogatorio delineado por la ley ha finalizado regularmente y la comisión ha transmitido el 4 de noviembre de 1997 a la presidencia de la Cámara de diputados y del Senado un proyecto de ley de revisión de la parte segunda de la Constitución junto con las relaciones tanto del presidente de la comisión y de los presidentes de los concretos grupos de trabajo, como de una relación de las minorías. Con el mes de enero de 1988, el plenum de la Cámara de diputados ha iniciado la discusión y la votación sobre el articulado presentado por la comisión bicameral y sobre las enmiendas (numerosísimas) propuestas por los diputados, llegando a la aprobación de los artículos referentes a la forma de Estado -que cualificaban en sentido regionalista la estructura del Estado: por un lado, ampliando las competencias de las Regiones y de los entes locales territoriales; por otro, reconociendo espacios efectivos de autonomía estatutaria a las Regiones, incluida la competencia para determinar la propia forma de gobierno y los caracteres del sistema electoral.

Pero la división entre las fuerzas políticas respecto de la nueva forma de gobierno (de tipo esencialmente semipresidencial) ha supuesto una grave situa- 
ción de impasse que ha terminado por interrumpir la discusión parlamentaria sobre la reforma de la Constitución, antes incluso de empezar a discutir la cuestión de mayor conflictividad, constituida por las nuevas normas en materia de ordenación de la justicia.

No obstante este resultado negativo, no sería correcto desconocer que esta última tentativa de revisión de la Constitución ha presentado significativos elementos novedosos, no sólo en relación al contenido sustancial de algunas propuestas, sino también bajo el perfil metodológico: tanto desde el punto de vista de los procedimientos previstos, como en orden a la profundización de algunos aspectos conceptuales subyacentes a las nociones de Constitución rígida y de revisión constitucional.

Por lo que se refiere a estos últimos, es preciso subrayar cómo, tanto con ocasión del iter de aprobación de la ley constitucional n. 1 de 1997, cuanto durante el debate inmediatamente posterior a la constatada ausencia en el Parlamento italiano de una mayoría suficiente para acordar cualificadas propuestas de revisión, aleteaba repetidamente el interrogante de si para alterar partes significativas del edificio constitucional era suficiente seguir el procedimiento ordinario de revisión constitucional, previsto en el art. 138 cost., o resultaba preciso dar vida a una verdadera y propia actividad constituyente. En otros términos, se planteaba si tan comprometida labor debía corresponder al Parlamento o a una específica asamblea dotada de poderes constituyentes, si debía intervenir el poder constituido o bien el constituyente.

Tal discusión estaba influenciada también por algunas posiciones teóricas de algunos sectores de la doctrina, que habían elaborado una rígida distinción conceptual entre actividad constituyente y de revisión constitucional, reclamando la atención sobre el hecho de que la Constitución italiana preveía un único procedimiento de revisión, no diferenciando según la materia y la naturaleza de las normas a reformar: a diferencia de lo que acaece en otros ordenamientos, donde se distingue entre macroconstitutional reform y piecemeal constitutional change (revisión de poco en poco), o bien entre poder constituyente originario, poder constituyente derivado y poder de revisión constitucional.

La preocupación por los aspectos procedimentales de la revisión constitucional testimonia -por otra parte- la creciente relevancia que, en la actual fase de transformación de los órdenes institucionales, adquiere la problemática de los procedimientos legales a seguir para modificar las cartas constitucionales. La atención se está transfiriendo progresivamente de los aspectos sustanciales a los aspectos formales, en el sentido de que el punto de equilibrio entre las fuerzas políticas debe ser buscado por anticipado, adelantándose a la fase de la discusión sobre los contenidos de las reformas que se quieren introducir, el acuerdo del iter a seguir para innovar el ordenamiento constitucional.

Tal tendencia puede tener diversas motivaciones, pero la notable relevancia de la cuestión debe ser atribuida en particular medida al hecho de que siempre la normativa sobre la revisión o la innovación puede ser insertada, con título pleno, entre aquel núcleo de normas que expresan los principios caracterizadores de un determinado orden constitucional. Se está en presencia, pues, de una Grundnorm, 
al mismo tiempo formal y sustancial, en el sentido de que la disciplina de las formas a través de las cuales se puede modificar la Constitución afecta a la forma misma de Estado, o mejor, constituye un elemento sintomático de la misma.

Si se comparte tal aseveración, es necesario convenir la oportunidad de superar la rígida antonomia entre actividad constituyente y de revisión constitucional, no ya en el sentido de negar el fundamento teórico a la misma necesidad política de las distinciones, sino más bien para evitar que en el interior del mismo instituto tengan lugar modificaciones del texto constitucional de relevancia sustancial bastante diferente: no resultaría congruente homologar desde el punto de vista procedimental las alteraciones de la carta constitucional que, aun sin afectar a los principios supremos del ordenamiento, incidan sobre cuestiones relevantes de la forma de gobierno o de Estado o del sistema de derechos fundamentales, con las alteraciones que atañan a aspectos no incidentes sobre principios cualificantes de la Constitución.

Se puede, en otros términos, afirmar que algunas importantes tendencias prevalentes del constitucionalismo se mueven en la dirección de admitir procedimientos de revisión "de geometría variable". Y sobre la base de tales presupuestos la doctrina italiana ha comenzado a introducir, también conceptualmente, una figura intermedia entre revisión de la Constitución y actividad constituyente, hablando en tal sentido de "reforma constitucional". Tal distinción ha sido hecha propia por el legislador, el cual, aprobando la ley n. 1 de 1997, ha introducido no ya un nuevo procedimiento de revisión de la Constitución, sino una derogación parcial de ésta, como consecuencia de la particular amplitud y relevancia de las disposiciones constitucionales que se entendia modificar.

Desde el punto de vista del procedimiento, el iter previsto se señalan algunas notas novedosas e indudable interés. En particular, pueden ser reseñados los tres siguientes aspectos:

a) el objeto de la revisión constitucional venía predeterminado, desde el momento en que el legislador ha circunscrito el ámbito de las normas a modificar a las disposiciones contenidas en la segunda parte de la Constitución (del art. 55 al art. 138). En otros términos, la discrecionalidad del legislador encontraba un vínculo no sólo de tipo material en los límites -formales y sustanciales, implícitos y explícitos- a la revisión constitucional, sino también de naturaleza objetiva, en el sentido de que el singular procedimiento previsto en la ley constitucional n. 1 de 1997 debía entenderse utilizable solamente para las propuestas de modificación de la Constitución que incidan sobre la forma de Estado, la forma de gobierno, la estructura bicameral del Parlamento y el sistema de garantías.

De ese modo, se ha introducido una neta diferencia entre actividad constituyente y de reforma de la Constitución, puesto que mientras esta última aparece predeterminada por el objeto de la alteración constitucional, la primera es -por su naturaleza- libre, no siendo concebibles límites ni sobre el objeto, ni en relación a los criterios directivos a seguir.

b) la iniciativa legislativa y los poderes instructorios han sido reservados a una especial Comisión bicameral, compuesta de 35 diputados y de 35 senadores 
nombrados por los Presidentes de las dos Asambleas parlamentarias respetando la proporción existente entre los grupos parlamentarios. A tal órgano especial ha sido atribuida la competencia para elaborar específicos proyectos de revisión constitucional, que han sido luego sometidos a la discusión y a la doble aprobación por parte de cada Cámara. Se subraya dicha reserva de competencia porque la misma ha supuesto una derogación de las disposiciones constitucionales ordinarias relativas a la titularidad de la iniciativa legislativa, que debería atribuirse al Gobierno, a los parlamentarios, a una fracción del cuerpo electoral y a las Regiones.

c) el procedimiento deliberativo resulta modificado en sentido sustancial, transformando de facultativa en obligatoria la sumisión de la ley de revisión constitucional al referéndum popular. Según el art. 138 cost. la solicitud de referéndum puede ser presentada solamente si el proyecto de ley resulta aprobado por una mayoría inferior al 75\%; en cambio, según el art. 4 de la ley n. 1 de 1997, la ley de revisión constitucional -una vez aprobada por las Cámaras- podría ser promulgada solamente si obtiene la aprobación del cuerpo electoral: se preveía, pues, un doble quorum, en cuanto resultaba preciso que en el referendum hubiese participado la mayoría de los que tuvieran derecho a votar y que la propuesta fuese aprobada por la mayoría de los votos válidos.

La singularidad del procedimiento previsto encuentra fundamento en la amplitud de las modificaciones que pretendian aportarse al texto de la Constitución y en la convicción de que resultara oportuno, en razón de la naturaleza y de la amplitud de la revisión, tanto racionalizar el procedimiento de elaboración del proyecto de revisión (confiando el poder de propuesta a una comisión específica), cuanto implicar necesariamente a los ciudadanos en la opción final (con independencia del consenso que la propuesta hubiese obtenido en el Parlamento).

Sin embargo, la doctrina no ha dejado de mostrar perplejidad en relación con la decisión de hacer concluir de modo necesario todo el procedimiento con un referendum. La opción de hacer obligatoria la intervención del cuerpo electoral, independientemente de la mayoría conseguida en el seno de las asambleas parlamentarias, ha sido considerada por algunos como inoportuna, en cuanto introduciría un elemento de desconfianza en la democracia representativa y podría generar consecuencias institucionales negativas caso de que, siendo aprobado el texto por una amplísima mayoría, fuese rechazado por el cuerpo electoral.

La decisión, por tanto, de prever que los ciudadanos se pronuncien sobre el texto completo en un único referéndum ha sido criticada con la argumentación de que el objeto del referéndum sólo puede versar sobre preguntas homogéneas y sustancialmente unitarias. Aludiendo, a tal efecto, a la consolidada jurisprudencia de la Corte constitucional sobre admisibilidad de solicitudes de referendum, incluso sólo abrogativos, algunos autores han entendido imposibles de proponer, por resultar inconciliables con la estructura del instrumento referendario, preguntas heterogéneas: así, se ha razonado que habría sido más correcto someter a la evaluación del cuerpo electoral no una única ley de revisión general de la segunda parte de la Constitución, sino una pluralidad de leyes de revisión de institutos o partes singulares. 
Aun conviniendo en la idoneidad del instituto referendario como expresión de la voluntad consciente de cada elector frente a textos normativos complejos y de contenido heterogéneo, somos de la opinión de que la última solución mencionada presenta tantas dificultades e inconvenientes prácticos como los que pretende resolver. Las primeras consisten en la individuación de cuáles y cuántas partes de la propuesta de reforma constitucional deberian ser examinadas por separado por el cuerpo electoral, puesto que bajo el mismo título se afrontan institutos jurídicos diferentes respecto a los cuáles un elector puede tener posiciones diversas. Las segundas se sintetizan en el riesgo de que aprobaciones referendarias diversas puedan quitar al texto constitucional la organicidad y coherencia interna que debe caracterizar toda propuesta de revisión de una parte total de la carta constitucional.

En conclusión, se es de la opinión de que la actual fase del debate sobre la reforma de la Constitución ha ofrecido aspectos significativos de reflexión teórica en lo referido a la temática de los procedimientos de revisión constitucional en los ordenamientos de Constitución rígida.

\section{LÍNEAS DE REFORMA DE LA ADMINISTRACIÓN PUBLICA Y NUEVOS CRITERIOS PARA LA DISTRIBUCIÓN DE COMPETENCIAS ADMINISTRATIVAS ENTRE ESTADO, REGIONES $Y$ ENTES LOCALES}

La revelada incapacidad del sistema para autorreformarse, innovando las propias disposiciones constitucionales, no debe, sin embargo, inducir a entender que actualmente la realidad italiana esté caracterizada por uná condición de estaticidad: al contrario, una rica, compleja y articulada normativa primaria está cambiando progresivamente el rostro de la administración italiana, incidiendo tanto sobre la distribución de competencias, como sobre el orden administrativo, como -en fin-sobre reglas de comportamiento y de funcionamiento.

Como es evidente, existe una evidente diferencia entre reformas constitucionales y administrativas: las primeras se basan sobre una explícita opción política que lleva a la aprobación de un nuevo texto constitucional; las segundas, en cambio, requieren un cierto período de metabolismo, necesitan no sólo de nuevas normas, sino también de cambios endógenos, necesitan de una mentalidad diver$\mathrm{sa}$, de nuevos comportamientos por parte de la burocracia. Por consiguiente, los cambios en la administración devienen de forma gradual, el elemento predominante es más bien la evolución que la discontinuidad, la continua adaptación de de la organización y de las funciones a la realidad externa que una brusca modificación de las normas de referencia, de los principios y criterios que regulan la actividad de la administración.

Sin embargo, aunque los efectos podrán verse solamente en el futuro, cabe señalar -por los fuertes elementos de novedad que contienen- algunas reformas incisivas introducidas por el legislador. En concreto, los pasos de dicha innovación están representados por la ley de delegación n. 59 de 1997, la ley n. 127 de 1997, el decreto presidencial n. 80 de 1998 y el decreto presidencial n. 112 de 1998. 
La ley n. 127 de 1997 se caracteriza porque ha reducido drásticamente el sistema de controles administrativos (regionales) en las relaciones con los municipios y las provincias, que no podía abolir dada la previsión constitucional del art. 130 cost.; ha modificado el status de los secretarios municipales y provinciales, transformándoles de funcionarios del Ministerio del Interior en cuerpo profesional autónomo regulado por una Agencia nacional específica; ha introducido medidas de simplificación, ampliando los sectores materiales susceptibles de deslegalización, de desconcentración normativa y de "despublicización" (depubblicizzazione).

Como es claro, la deslegalización supone limitar el peso y la cantidad de la actividad legislativa incrementando el poder decisional de los aparatos de gobierno; la desconcentración normativa, en cambio, está estrechamente ligada con el fenómeno de la descentralización, en cuanto reúne en sí tanto los efectos de la deslegalización como los de la descentralización del decision making power. En fin, el fenómeno de la "despublicización" se produce cuando las funciones continúan siendo ejercitadas por la administración pública, pero son reguladas por institutos de derecho privado y no por los de derecho público. Se trata de un abanico de opciones que ha incidido profundamente sobre el sistema de fuentes, poniendo junto al tradicional criterio de jerarquía, el de competencia.

A su vez, el decreto legislativo n. 80 de 1998 reviste una particular relevancia porque, de un lado, ha acentuado los procesos de privatización de la relación de trabajo del personal en el interior de las administraciones públicas y ha definido los deberes propios de la dirección pública, separándoles de las competencias específicas de los órganos de dirección político-administrativa; de otro lado, ha reformado el contencioso jurisdiccional en materia de relación de trabajo atribuyendo la competencia sobre las controversias relativas a las relaciones de trabajo al juez ordinario, en vez de al administrativo.

Sin embargo, desde el punto de vista genuínamente constitucional, el mayor interés debe ser dirigido a la ley de delegación n. 59 de 1997 y del correlativo decreto legislativo n. 112 de 1998, desde el momento en que tales fuentes han innovado en medida sustancial los criterios de distribución vertical de las funciones administrativas, incrementando la descentralización funcional y política. Se trata de una ley de contenidos bastantes complejos, que ha intentado afrontar muchos ámbitos de la organización del Estado: basta considerar que, además de impulsar una nueva fase de descentralización a través de la transferencia de nuevas funciones administrativas en favor de las Regiones y de los entes locales, ha previsto -entre otras cosas-, por un lado, la reforma de los aparatos ministeriales, mediante la supresión, la fusión, la redefinición de las tareas de los ministerios; por otro lado, la introducción de la autonomía en el interior de un sistema educativo, extendiendo algunos principios organizativos propios de la Universidad también a las escuelas elementales, medias y superiores.

Pero, sobre todo, la ley n. 59 de 1997, aprobada algunos meses después de la constitución de la comisión parlamentaria prevista en la ley constitucional n. 1 de 1997, ha realizado -en materia de relaciones entre el Estado, Regiones y sistema de autonomías locales- una verdadera y propia reforma constitucional "paralela" a las labores de la Comisión bicameral para las reformas constitucionales: ello 
ha sido así en cuanto ha incidido en aspectos de la forma de Estado, aun sin modificar el texto literal de la carta constitucional. Operando hábilmente entre las mallas de la normativa constitucional vigente, el legislador ha logrado plantear sobre la base de nuevos presupuestos la repartición de competencias entre los diversos niveles institucionales.

Se trata de las terceras transferencias que han afectado -desde la entrada en vigor de la Constitución republicana a hoy- el proceso de regionalización de la administración pública. Las primeras -de 1972- fueron objeto de gran atención, por haber mantenido una interpretación restrictiva de las materias de competencia regional y por haber transferido -en consecuencia- solamente algunas funciones administrativas ejercidas por los ministerios, sin considerar las ejercidas por los numerosos entes públicos nacionales existentes. Las segundas transferencias -en 1977- han sido evaluadas positivamente por su amplitud, su organicidad, por la atribución directa de funciones también a favor de los Ayuntamientos en las materias de interés exclusivamente local.

Sin embargo, el proceso de devolución de ulteriores competencias en favor de las Regiones permaneció largamente bloqueado. Hubieran debido realizarse más transferencias competenciales recientemente como consecuencia del resultado positivo de algunos referenda que abrogaron las leyes creadoras de ministerios que ejercían funciones propias de materias reservadas a las Regiones según el art. 117 cost. (agricultura, turismo, espectáculo): no obstante, ello no ha sucedido porque el Parlamento ha preferido absorber los efectos del referéndum sin "particulares daños" para las instituciones centrales; ha preferido conservar para la administración central el ejercicio de dichas actividades administrativas, asignando las competencias en materia de turismo y de cultura a la Presidencia del Consejo de ministros y las de agricultura a un nuevo ministerio, denominado "Ministerio de recursos agrícolas, alimentarios y forestales".

Respecto a las precedentes experiencias, la ley n. 59 de 1997 se distingue por algunas significativas innovaciones. En primer lugar, confiere funciones a las Regiones y a los entes locales también en materias extrañas al elenco de materias de competencia legislativa del art. 117 cost., y a los sectores orgánicos individualizados por los precedentes decretos de transferencia (ordenamiento y organización administrativa de las regiones, servicios sociales, desarrollo económico, orden y utilización del territorio). Usando el criterio de la competencia residual en favor de las autonomías regionales y locales, define elencos de materias cuyas funciones administrativas deben continuar siendo ejercidas por el Estado, mientras que confía las restantes a las Regiones, a las Provincias y a los Municipios.

La ley introduce, por primera vez, un criterio de repartición de competencia basado sobre "enumeraciones de las competencias centrales". En otros términos, la ley singulariza las materias que permanecen en la competencia exclusiva del Estado (en concreto, 16, entre las cuáles se encuentran : asuntos exteriores, defensa y fuerzas armadas, relaciones con las confesiones religiosas, tutela de los bienes culturales y del patrimonio histórico, ciudadanía e inmigración, moneda, orden público, justicia, seguridad social, investigación científica, etc.); mientras afirma el principio de que en las otras materias la actividad 
administrativa debe ser asignada a las Regiones, a las Provincias y a los Municipios. Consiguientemente, el decreto legislativo n. 112 de 1998 ha podido descentralizar el ejercicio de algunas significativas funciones en materia de industria, protección de la naturaleza y del ambiente, de la instrucción escolar, bienes culturales.

En segundo lugar, la ley n. 59 de 1997 y el decreto n. 112 de 1998 que la desarrolla han asumido el principio de subsidiariedad como principal criterio para repartir la competencia entre el centro y la periferia.

El principio de subsidiariedad no distribuye directamente las competencias, sino que constituye un criterio de inspiración en el momento de decidir qué funciones y qué materias deben ser descentralizadas; al mismo tiempo, representa un parámetro para controlar la coherencia, la racionalidad de las opciones realizadas por el legislador. Tal principio es seguramente innovador porque supera el criterio de la uniformidad en la distribución de las competencias y presupone un sistema de descentralización que resulta, al mismo tiempo, dinámico y diversificado. En efecto, la subsidiariedad debería imponer la consideración de la capacidad concreta de los distintos entes locales para el ejercicio de determinadas funciones, impidiendo el razonamiento por categorías generales. En principio, un aplicación coherente del mismo debería favorecer la formación de un sistema policéntrico, dando vida, con una distribución homogénea de las competencias entre todos los entes del mismo tipo y del mismo nivel, a sistemas regionales diferenciados. De hecho, en la individualización concreta del ámbito territorial al que asignar el ejercicio de determinadas funciones, deberían tenerse en cuenta dos criterios directivos:

a) el criterio de adecuación, relativo a la efectiva idoneidad organizativa de las administraciones concretas para garantizar el ejercicio de las funciones;

b) el criterio de diferenciación, en el sentido de que en el momento de atribuir las funciones se deben considerar también las diversas características territoriales, demográficas y estructurales de los entes descentralizados.

En otros términos, una eficaz atribución de las diversas funciones sobre el total del territorio nacional, no debería prescindir del análisis de las concretas situaciones organizativas. Lo que debería abrir la vía al reconocimiento del papel organizador de las regiones en cuanto a autonomías locales, valorando la previsión del art. 3 de la ley 142 de 1990, el cual atribuye a las Regiones la tarea de "Organizar el ejercicio de las funciones administrativas a nivel local a través de los Municipios y las Provincias". En efecto, qué nivel, si no el regional, aparece como más idóneo para evaluar si los Municipios de un determinado territorio o las Provincias son realmente adecuadas para ejercitar las funciones que les son atribuidas o si, por el contrario, las mismas pueden ser ejercitadas más eficazmente por otros entes o niveles institucionales.

El dinamismo que caracteriza las relaciones entre Estado central y ordenamientos territoriales descentralizados hace que resulte oportuno conseguir la efectiva distribución de las competencias no tanto aplicando rígidamente el catálogo, el elenco de las materias, cuanto a través de un proceso evolutivo, cuyo trend aparece marcado o por el papel de la jurisprudencia o por la mediación institucional. 
Las dos vías no son alternativas, sino que poseen un valor bastante diferente. En el primer caso, se confía a los jueces -en particular a los constitucionales-ya para resolver el contencioso que se produce entre los diversos niveles constitucionales, ya para descubrir en el exámen de las tendencias jurisprudenciales consolidadas el parámetro de referencia a fin de definir el equilibrio entre Estado central y comunidad descentralizada en el ejercicio de una determinada competencia.

En Italia, se ha confiado en el pasado casi exclusivamente el papel mediador $y$ distribuidor de las competencias al juez constitucional, el cual ha suplido en numerosas decisiones la falta de instrumentos institucionales y la carencia legislativa recurriendo a la noción -de derivación genuinamente jurisprudencial- de leal colaboración.

Dicha orientación jurisprudencial refuerza la convicción de que es preferible no tanto operar sobre la distinción rígida de los ámbitos materiales de competencia, como sobre la individualización de los instrumentos de enlace y colaboración, así como que el papel equilibrador del juez constitucional no puede representar la vía maestra en la concreción puntual de los respectivos ámbitos de competencia. El confiar a un "tercer" órgano la tarea de resolver las controversias entre los diversos niveles institucionales de gobierno sobre la puntual distribución de las competencias puede constituir una solución marginal: como se ha puesto relieve por sectores autorizados de la doctrina y se confirmado en la práctica, el papel de la justicia constitucional resulta "sin duda más casual, discontinuo, desenfocado, contingente" en cuanto se aleja de los cánones tradicionales de la jurisdicción, de la verificación de la conformidad con la Constitución de las normas primarias, para caracterizarse como árbitro de los conflictos.

De aquí la necesidad de descubrir procedimientos de naturaleza más política, de tipo pacticio y consensual; de lograr una definición concordada del reparto de competencias -que pueden obtener logros generales-, si se singularizan ámbitos competenciales valederos para todas las Regiones, o individuales, si la fase negocial implica una sola región.

Algunos pasos en tal dirección ha sido dados por el decreto n. 112 de 1998 a propósito -p. ej.- del sector de los bienes culturales, el cual, por un lado, prefiere llegar a la repartición de las competencias no en vía abstracta y normativa recurriendo a una atribución directa, sino a través de procedimientos participativos; por otro lado, concreta en el ámbito regional la sede idónea para la puntual determinación de los respectivos deberes, acreditando la idea de soluciones no homogéneas, sino diferenciadas según la distinta realidad. Considérese, a este respecto, el art. 150 del decreto que asigna a una comisión paritaria, compuesta de cinco representantes del Ministerio de bienes y ambiente y de cinco representantes de los entes territoriales, la competencia en tema de gestión de museos; o bien los arts. 154 y 155 , que instituyen en cada Región de estatuto ordinario una comisión mixta para los bienes y las actividades culturales con el deber de armonizar y coordinar, en el territorio regional, las iniciativas, haciendo converger en un plan común plurianual y anual de valoración de los bienes culturales y de promoción de las actividades correspondientes.

El paso de un modelo estático -por catálogos- a uno de tipo procedimental y consensual aparece particularmente idóneo para la actuación de los criterios de 
adecuación y subsidiariedad que deberían informar -según los criterios directivos de la ley de delegación n. 59 de 1997- la distribución de las competencias entre los diversos niveles institucionales. Principios que deberían inducir a confiar la organización y la gestión de los bienes culturales y ambientales a los entes que tienen el gobierno del territorio más próximo y la competencia para determinar un desarrollo equilibrado del mismo, siempre que ello sea racional en orden al efectivo ejercicio de las funciones; viceversa, la imposibilidad económica o estructural de un ente para valorar una determinada manifestación cultural debería conducir a confiar la gestión a un nivel institucional superior.

No todas las potencialidades recabables de la ley n. 59 de 1957, sin embargo, han sido desarrolladas mediante delegación legislativa. No parece, en efecto, que del exámen general del decreto n. 112 de 1998 emerja un modelo de descentralización autonómico del Estado realmente alternativo al producido por el decreto n. 616 de 1977, salvo la ampliación cuantitativa -ya bastante significativa- de las funciones descentralizadas. Más bien diversos elementos inducen a considerar el último decreto de transferencia más un modo de completar el proceso inacabado de descentralización de las funciones impulsado en los años 70 , que un vuelco del mismo sobre bases cualitativamente nuevas.

La opción misma del modelo institucional perseguido se presenta incierto, desde el momento en que en su seno conviven opciones diversas: se oscila entre la creación de un sistema binario, basado en la presencia paralela de administraciones locales y administraciones periféricas del Estado, y el reconocimiento de la existencia, a nivel local, de una administración única; entre una descentralización de las funciones administrativas bien a favor de las autonomías institucionales o bien del pluralismo social, según deriva del inacabado debate entre subsidiariedad vertical u horizontal; entre una descentralización de bases regionales, o bien articulada sobre dos niveles locales en recíproca competición -el regional y el municipal o provincial.

Además, en la estructura del decreto n. 112 de 1998, permanece una de las características que había caracterizado negativamente las transferencias precedentes, como es la separación temporal entre la descentralización de las funciones y la reforma de los aparatos ministeriales.

Se puede afirmar en síntesis que el legislador ha codificado las premisas para una redefinición estructural de la administración pública italiana y, en su seno, de las relaciones entre el centro y la periferia; sin embargo, los primeros pasos dados se presentan inciertos y llenos de dificultad a causa de las resistencias internas a la administración pública y al todavía no aclarado papel de las Regiones en el proceso de reforma del Estado.

\section{LAS PROSPECTTVAS DE DESARROLLO DEL SISTEMA POLÍTICO ABIERTAS POR LAS SOLICITUDES DE REFERÉNDUM ABROGATIVO DE LA LEY ELECTORAL}

En Italia continúa bastante vivo el debate sobre los caracteres de la representación política y sobre los instrumentos que pueden ser activados de manera 
útil para mejorar su cualidad. Entrados los partidos políticos en una crisis de identidad, tanto por causa de los llamativos éxitos de las investigaciones judiciales sobre la corrupción política, como del agotamiento de la fase institucional que se inició con la aprobación de la Constitución republicana y la consolidación del régimen democrático tras la caída del régimen fascista, la atención prevalente -tanto de la doctrina constitucionalista y politológica, como del sistema político- se ha vuelto hacia la problemática de los sistemas electorales: considerados la llave más fácil tanto para remodelar el sistema de partidos como para influir sobre los caracteres de la forma de gobierno.

No es casual que en estos últimos años se hayan innovado radicalmente las modalidades de elección de los órganos de todos los nieveles institucionales: desde la Cámara y Senado a los consejos regionales, a los Alcaldes y Presidentes de Provincias.

Es evidente, en efecto, que en los ordenamientos constitucionales contemporáneos las elecciones suponen una pluralidad de funciones: confieren a los órganos una legitimación democrática, manifiestan el grado de consenso social hacia las instituciones, contribuyen a determinar la dirección política, permiten verificar la coherencia de los comportamientos y la correspondencia de las posiciones asumidas por los órganos electivos con las orientaciones de la mayoría del cuerpo electoral; singularizan las elites políticas a las que compete la formación de las decisiones políticas y su desenvolvimiento práctico.

Respecto de esta pluralidad de funciones, las propuestas más recientes de revisión de los mecanismos electorales se han dirigido, sobre todo, por un lado a incidir sobre la formación de las elites políticas y, por otro, a reforzar la claridad y la coherencia de la orientación política del gobierno. De hecho, las dos palabras en este sentido que amplios sectores de la doctrina y de las formaciones políticas repiten con mayor frecuencia pueden ser sintetizadas en la voluntad de dar vida a un sistema político que sea bipolar -esto es, que se funde sobre dos formaciones políticas contrapuestas, incluso aunque estén formadas en su interior por una pluralidad de fuerzas políticas expresivas del rico pluralismo social y político italiano- y unívoco en la opción de una mayoría y de una determinada orientación política -de modo, p. ej., que del resultado electoral emerja con claridad una mayoría política, con capacidad para durar la legislatura entera, sin que se produzcan cambios de mayoría sin la previa convalidación del cuerpo electoral.

A tal fin se ha producido una orientación hacia sistemas de "democracia inmediatan, es decir, que consientan que del voto surja una directa y clara indicación de la orientación política, de la mayoría y del leader político, aun sin prever la elección directa del Presidente del Consejo de ministros. Y la fórmula electoral entendida más idónea para conseguir tal objetivo ha sido concretada en el principio mayoritario, si bien corregido a la luz de la especificidad histórica del sistema político italiano.

Tales resultados han sido facilitados, frente a la parálisis del proceso de revisión constitucional que se ha apuntado al inicio de esta crónica, por la elección de los constituyentes de no constitucionalizar las características del sistema electoral. Incluso si en el debate en la asamblea constituyente numerosos componen- 
tes se expresaron a favor de la constitucionalización de la representación proporcional, resulta arduo encontrar en el texto de la carta constitucional la presencia de disposiciones que tutelen directamente el principio proporcional; más bien lo que se puede hallar es el principio de la tutela del pluralismo de partidos, esto es, una tutela indirecta no tanto del sistema proporcional, cuanto de mecanismos electorales que permitan la representación asamblearia de las voluntades minoritarias expresadas por el cuerpo electoral.

Esto ha facilitado pasar mediante legislación ordinaria de un sistema fuertemente proporcional a uno mayoritario atemperado. Sin embargo, debe tenerse presente que la opción a favor de sistemas de "democracia inmediata" no ha sido el fruto de una voluntad autónoma del Parlamento y del sistema de partidos, sino la resultante de un proceso provocado por el recurso al único instrumento de democracia directa que la Constitución prevé: el referendum abrogativo.

En efecto, el legislador italiano ha modificado radicalmente la ley electoral, pasando -como es claro- de un sistema proporcional a uno de prevalente caracterización mayoritaria -en el sentido de que el $75 \%$ de los escaños de la Cámara de diputados y tres cuartos de los escaños del Senado son asignados en colegios uninominales a los candidatos que han alcanzado el mayor número de votos, mientras el remanente se reparte con el criterio proporcional- como consecuencia del resultado de un importante referéndum -celebrado el año anterior- que determinó, aunque fuera sólo para el Senado, la introducción de un mecanismo enteramente mayoritario.

La tensión existente entre democracia representativa y democracia directa, inmanente al mismo instituto referendario, se ha revelado de manera particularmente clara en el caso específico de la legislación electoral: la experiencia italiana manifiesta una variedad de orientaciones entre la "Voluntad" del cuerpo electoral, que se ha expresado de forma bastante univoca a favor del principio mayoritario, y las determinaciones del Parlamento, orientadas a reconocer la validez perdurable del criterio proporcional.

Así es que, frente al referéndum de 1992, que había determinado un sistema para la elección del Senado enteramente mayoritario, las Cámaras han aprobado un sistema solo parcialmente mayoritario, en el que permanecen aspectos propios de los sistemas proporcionales. Y tal contraposición se está volviendo a reproducir si se considera que un "comité promotor" -compuesto de autorizadas personalidades políticas pertencientes a las más diversas fuerzas- ha recogido las quinientas mil firmas precisas para presentar una solicitud de referéndum, con la finalidad de abrogar aquellas normas de la ley electoral de 1993 que atribuían una parte de los escaños con el método proporcional.

En consecuencia, en caso de que el resultado del referéndum supere positivamente los controles de admisibilidad de la Corte constitucional y de legitimidad de la Oficina central para el referéndum, el cuerpo electoral podría ser llamado en 1999 a pronunciarse nuevamente sobre el sistema electoral: le sería pedido de nuevo que decidiese sobre las características del sistema electoral, dada la incertidumbre y las divisiones de las fuerzas políticas sobre la cuestión. Cabe recordar, en efecto, que la materia electoral constituía uno de los temas en discusión de la Comisión parlamentaria para las reformas constitucionales y que los partidos te- 
nían sobre el tema ideas expresas no homogéneas: se diferencian, ante todo, entre los partidarios del sistema mayoritario y los sostenedores -pertenecientes tanto a la mayoría del gobierno como a la oposición- de un retorno a criterios de tipo proporcional; $\mathrm{y}$, después, dividiéndose entre los promotores de sistemas mayoritarios a una vuelta o a doble vuelta.

Probablemente, una vez más será el cuerpo electoral el llamado a cortar el "nudo gordiano" que la representación política no parece capaz de deshacer. 